This item was submitted to Loughborough's Research Repository by the author.

Items in Figshare are protected by copyright, with all rights reserved, unless otherwise indicated.

\title{
Computer-aided recycling process planning for end-of-life electrical and electronic equipment
}

PLEASE CITE THE PUBLISHED VERSION

PUBLISHER

Professional Engineering Publishing / @ IMechE

VERSION

VoR (Version of Record)

LICENCE

CC BY-NC-ND 4.0

\section{REPOSITORY RECORD}

Abu Bakar, Muhammad S., and Shahin Rahimifard. 2019. "Computer-aided Recycling Process Planning for End-of-life Electrical and Electronic Equipment”. figshare. https://hdl.handle.net/2134/5058. 
This item was submitted to Loughborough's Institutional Repository (https://dspace.lboro.ac.uk/) by the author and is made available under the following Creative Commons Licence conditions.

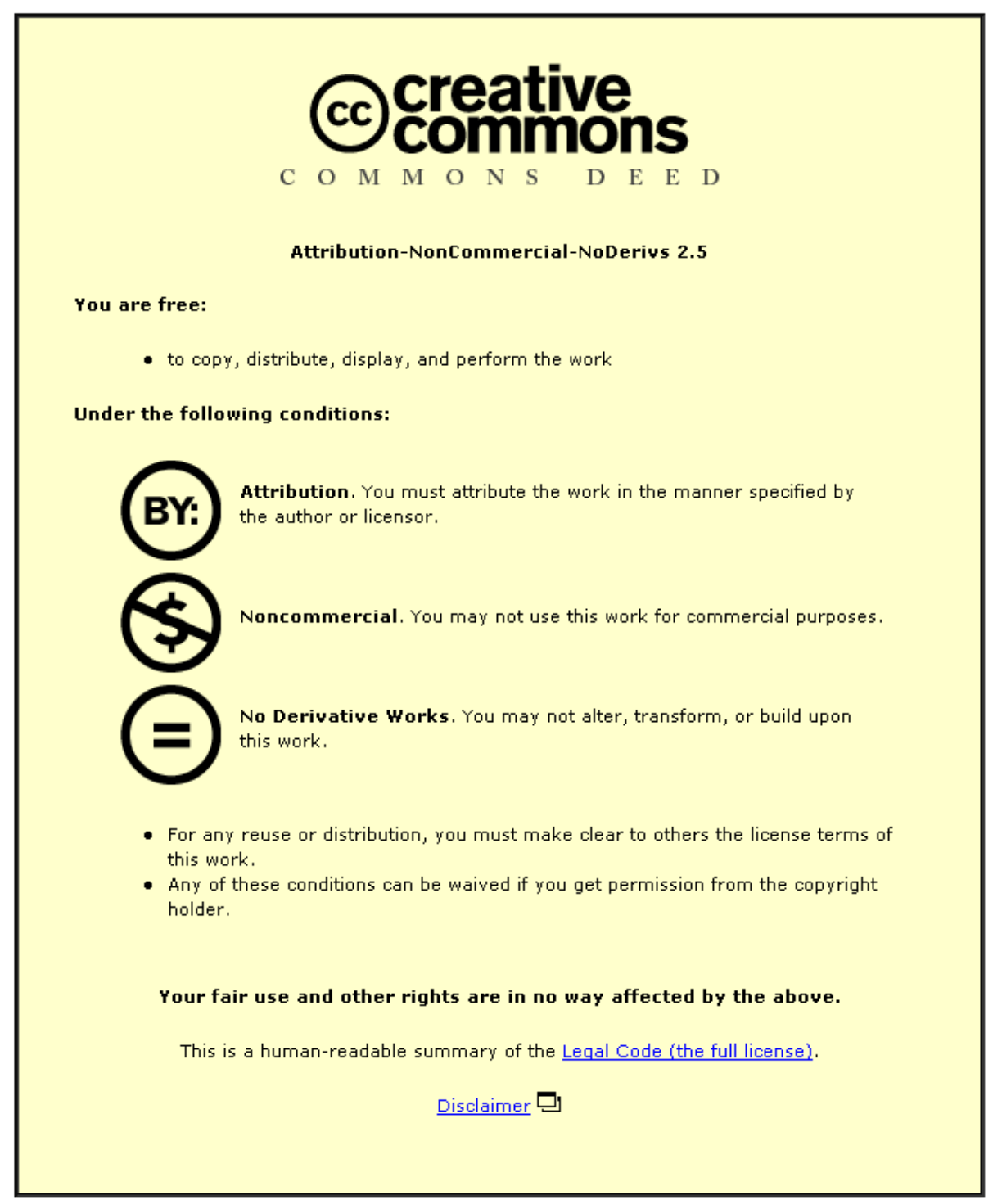

For the full text of this licence, please go to: http://creativecommons.org/licenses/by-nc-nd/2.5/ 


\title{
Computer-aided recycling process planning for end-of-life electrical and electronic equipment
}

\author{
M S Abu Bakar* and S Rahimifard \\ The Centre for Sustainable Manufacturing and Reuse/Recycling Technologies, Loughborough University, \\ Loughborough, UK
}

The manuscript was received on 4 December 2006 and was accepted after revision for publication on 3 April 2007.

DOI: $10.1243 / 09544054 J E M 801 S C$

\begin{abstract}
The significant environmental cost associated with management of products at the end-of-life has resulted in the emergence of 'producer responsibility' legislations to encourage increase in recovery and recycling practices. In the case of electrical and electronic equipment, one such legislation, namely the 'Waste from Electrical and Electronic Equipment Directive', requires manufacturers to assume financial and legal liability for recovery and recycling of their products at the end-of-life. The current recycling applications of electrical and electronic waste are often developed on ad hoc basis and mainly attributable to the hidden economic value within used products. However, owing to stricter regulations on end-of-life product recycling, it is now essential to evaluate the recycling costs and environmental benefits of reclaimed products and materials as well as the selection of appropriate recycling strategy. The present paper describes the initial investigation in the realization of a computer-aided recycling process planner for electrical and electronic products. The assertion made is that such a systematic approach to producing bespoke eco-efficient recycling process plans for individual products will significantly improve the value recovery from recycling activities.
\end{abstract}

Keywords: recycling process planning, WEEE, end-of-life

\section{INTRODUCTION}

The production of electrical and electronic equipment (EEE) is increasing owing to technological innovation, market expansion, shorter product life cycles, and improvements in economy [1]. This development is leading to a huge increase in waste from electrical and electronic equipment (WEEE). It had been predicted that 7.3 million tonnes of WEEE were created in Europe in 2002, with an estimated annual growth rate of 3-5 per cent [2]. Although a part of this waste (mainly white goods) has been recycled, a large proportion of WEEE that contains potentially recyclable materials ends up in landfills. The consumption of scarce materials in the manufacture of EEE and its disposal to scarce landfill sites along with environmental problems caused by electrical and electronic (E\&E) waste has resulted in the introduction

*Corresponding author: Mechanical and Manufacturing Engineering, Loughborough University, Wolfson School of Mechanical and Manufacturing Engineering, Loughborough, LeicestershireLE11 3TU, UK.email:m.s.abu-bakar@lboro.ac.uk of a European producer responsibility directive for such waste, namely the WEEE directive.

At present, a limited volume of WEEE is collected and sent for processing to authorized recovery facilities. The recovery treatment of this waste currently is mainly based on the capabilities and available resources within these facilities, without any detailed considerations of environmental benefits of such recycling activities. Furthermore, these recycling activities are solely focused on the reclamation of most valuable components and materials, with a substantial amount of waste still being sent to landfill in the form of shredder residue. This highlights the need to improve the value recovery from such recycling activities to ensure a larger proportion of components and materials being recovered from WEEE. Hence, the decision on the selection of the most appropriate recycling processes needs to be based on the consideration of both the environmental and economical factors involved in WEEE recycling.

The research reported in the present paper aims to take advantage of the benefits provided by a systematic approach to process planning experienced in 
manufacturing applications [3] and to apply a similar principle to increase the efficiency of recycling activities. This paper presents initial considerations on the development of a computer-aided recycling process planner (CARPP) for electrical and electronic products based on environmental and economical assessment of different recycling scenarios. A brief review of the most relevant research together with an end-of-life (EOL) model for WEEE based on current recycling practices are provided in the initial sections of the current paper. The main sections describe a framework for recycling process planning together with the design and specification of a CARPP system.

\section{BRIEF REVIEW OF THE MOST RELEVANT RESEARCH}

The two important aspects considered in EOL research are recycling cost and environmental impact. These aspects should form the basis for any recycling strategy selection. Existing research, however, usually focuses on the economic aspects of EOL recycling. Most of the studies for recycling cost estimation have adopted a bottom-up approach where the estimation is conducted based on operation breakdown and summation of detailed cost items. For material recovery, several studies estimate recycling cost including disassembly cost, shredding and separation cost, disposition cost, and revenue from reclaimed materials. Reimer et al. [4] have proposed a recycling model to minimize the cost of different EOL activities such as collection, disassembly, and material separation sequences by establishing separate models for each activity and using genetic algorithms. Other examples include Tsao [5] and Stutz [6]. Much attention is paid to disassembly as it plays an important role in the whole recycling economics. Tang et al. [7] and Gerner et al. [8] systematically investigated the disassembly sequence and related operations so that disassembly cost can be optimized.

On the other hand, there is also an ongoing research to evaluate the environmental performance of different recycling scenarios. There is the life cycle assessment (LCA), which is commonly used to determine the environmental impacts of a product throughout its lifetime. Some studies have incorporated both cost estimation and environmental impact estimation. For example, Lee et al. [9] tried to find an alternative that can both maximize profit and minimize environmental impact; they use a coffee maker as an example. Zhang et al. [10] adopted the analytical hierarchic process (AHP) to find the best recycling strategy. The AHP-based evaluation considered environmental impact, cost, and reclaimed materials as the major criteria for strategy determination. Huisman et al. [11] described 'the quotes for the environmentally weighted recyclability' (QWERTY) approach, which focuses on the determination of environmentally weighted recycling scores. The concept describes the environmental performance of recycling of waste products. To reduce the environmental impact of EOL EEE and increase the economic benefits at the same time, the CARPP described in the current paper integrates the environmental and economic concerns to apply a holistic assessment to facilitate E\&E waste recycling.

\section{AN END-OF-LIFE MODEL FOR WEEE}

EEE is typically divided into large household appliances, information technology (IT) equipment, consumer equipment, and small electrical appliances. Currently, large appliances are mainly collected together with scrap metals at the municipal collection centres. After dismantling and removal of polychlorinated biphenyl (PCB) capacitors, and mercurycontaining components (switches), this fraction is added to scrap metals and mechanically separated in coarse shredding facilities. IT equipment and appliances with cathode ray tube (CRT) are gathered separately and dismantled. Casings (plastic and partly wood) are separated and presently still landfilled. Hazardous components such as large capacitors and buffer batteries and accumulators as well as liquid crystal displays (LCDs) are removed and specially treated as hazardous waste. Small electrical appliances are at first submitted to the removal of hazardous components (for instance switches and relays containing mercury, PCB capacitors, batteries, etc.) and these parts are forwarded to specific treatment options according to the special type of pollutant. The appliances of which the hazardous fractions are removed are mechanically processed. By this treatment procedure mainly the metal-containing fraction is recovered. The remaining fraction, containing mainly plastic, is thermally treated or landfilled. According to the Association of Plastics Manufactures in Europe (APME), WEEE contains approximately 38 per cent ferrous metals, 28 per cent non-ferrous metals, 19 per cent plastics, and 4 per cent glass. As WEEE is a mixture of various materials, it can be regarded as a resource of metals, such as copper, aluminium, gold, and plastics. The complexity of materials contained within each product and the huge variety of products in EEE make ad hoc applications of WEEE recycling highly ineffective in terms of both ecology and economy. The review of these EOL activities within different recovery and recycling facilities has highlighted that there is little consistency regarding WEEE recycling owing to lack of formal procedures to determine the best course of action for individual products. A model encompassing different 


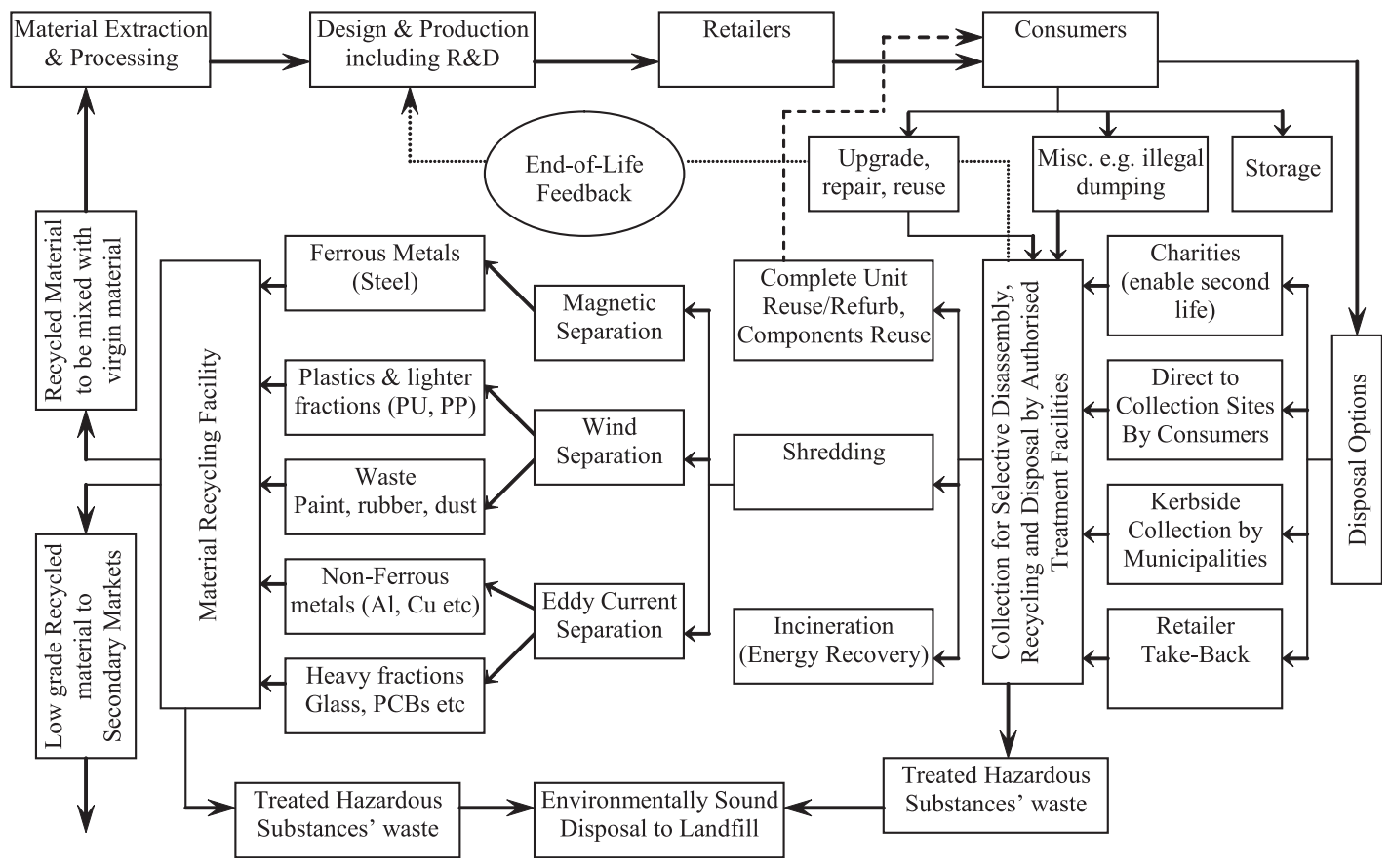

Fig. 1 EOL management model for EEE

activities in EOL management of WEEE is presented in Fig. 1.

The existing and future concerns on disposal and recycling of WEEE highlight the need for a systematic management tool effectively to maximize the recyclability of EOL products and minimize the environmental impact of recycling and disposal. The following sections describe a systematic approach for CARPP, which is set to improve the current state of E\&E recycling.

\section{AN INTEGRATED FRAMEWORK FOR EEE RECYCLING}

The general environmental concerns with respect to discarded EEE are related to conservation of resources, potential toxicity after discarding, and the reduction of landfill and incineration volumes. Traditionally, take-back initiatives were developed for products with a positive EOL value such as copiers, medical equipment, or computer mainframes. However, at present, a large proportion of consumer electronic products have a negative EOL value, which means that take-back initiatives for these products will only be developed when driven by legislation. Clearly, the major challenge for the next generation of recovery facilities will be to minimize the overall costs for EOL treatment of discarded products (i.e. economically justifiable) and to maximize the environmental benefits of such activities (i.e. ecologically friendly). Therefore, any comprehensive framework for recycling process planning should include the concurrent considerations of relevant environmental and economic parameters as well as the legislative requirements. Figure 2 depicts one such framework, referred to as the $\mathrm{Eco}^{2}$ (ecological and economical) framework, for the generation of recycling process plans. A further complexity related to the recycling process planning is the required product data, which typically can be obtained from the product design. However, currently in most cases access to

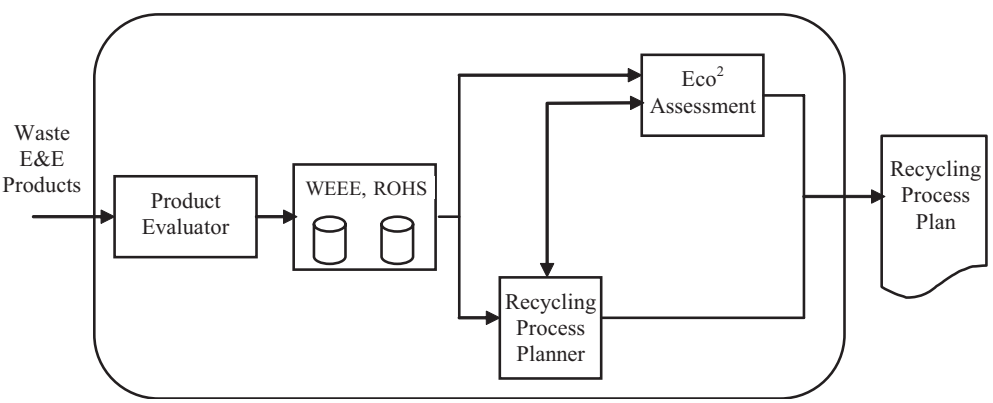

Fig. 2 Major tasks in $\mathrm{Eco}^{2}$ framework 
initial product design data is not available or access to it is restricted. Therefore, a product evaluation stage has been included as part of the framework to generate the data required for recycling process planning.

\section{COMPUTER-AIDED RECYCLING PROCESS PLANNER}

Process planning in manufacturing applications is an established field that comprises the selection and sequencing of processes and operations to transform a chosen raw material into a finished component in discrete part manufacture. Computer-aided process planning (CAPP) has nowadays become common place in most applications and is preferred over the traditional manual process planning to introduce consistency in planning. There are two basic approaches to CAPP: the generative and variant approaches [3]. The generative approach is based on developing a completely new process plan for every part. It uses the decision logic, formulae, algorithms, and geometric analysis and is considered to be the best approach for manufacturing process planning. On the other hand, the variant approach is similar to the manual process planning as it retrieves an existing standard plan and modifies it to suit the given product. This standard plan is usually for a complex product that incorporates all the features for a particular group or family of products. The process plan for the product under consideration can be compiled by retrieving those processes in the standard plan that are relevant and grouping them to generate a customized process plan for the product.

In the case of recycling process planning, the nature and range of processes is not as complicated as in manufacturing and there is a huge potential of the reuse of the recycling process plans owing to the products, parts, and components commonality.
The present authors argue that the adaptability and flexibility of the variant process planning makes such an approach particularly suitable for the recycling process planning. Therefore, based on the product categories used in the WEEE directive, a variant-based approach to recycling process planning is developed. In this approach, the generation of the process plan starts with evaluation of the product under consideration to identify the valuable parts and hazardous substances that need to be dismantled and removed in the initial stages. Then, depending on the remaining material mix in the hulk, a number of shredding and separation processes are considered and assigned before the final stage, namely the operations required for safe disposal of remaining material (commonly referred to as shredder residue). Based on this variant approach, and using the Microsoft Excel, a CARPP has been implemented that incorporates a simple and yet effective generic methodology for the multiobjective decision-making problem of material recycling and disposition of E\&E products (see Fig. 3(a)). The CARPP starts by gathering the material breakdown of given product and passes this information to the recycling process planner module. It also identifies any hazardous material requiring selective treatment to assign feasible and appropriate recycling processes. The CARPP contains the database of recycling processes that have been identified through the survey of existing applications, and are grouped together in this database. Information obtained from the product evaluator module controls the recycling processes that are included in the recycling process plan, as each product attribute is linked to one or more sub-operations in the process plan generated for an individual product. The CARPP system also calculates and analyses the environmental impact and cost of the recycling processes as part of the $\mathrm{Eco}^{2}$ assessment module. A typical recycling process plan for a refrigerator generated by the CARPP is illustrated in Fig. 3(b).
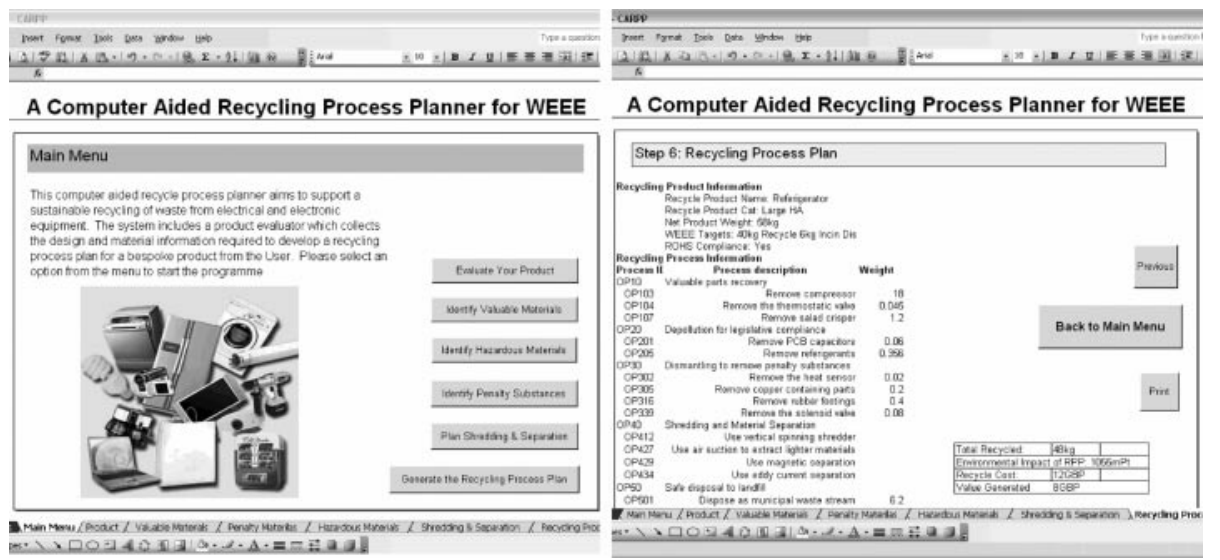

Fig. 3 Screenshots of CARPP: (a) main menu of CARPP; (b) a typical recycling process plan 
Typically the quality of variant-based CAPP is very much dependent on the gradual improvement of the 'generic process plan' used as the core of planning activities and the heuristics (or algorithm) used to select a subset of operations and suboperations for a product under consideration. This can only be achieved through a large number of case studies, which extend and improve the information and knowledge stored in such CAPP. Hence, a comprehensive programme of case studies is planned based on different categories of products in the WEEE such as large household appliances, consumer equipment, small household appliances, IT equipment, etc. to improve the decision-making process at the heart of the CARPP.

\section{CONCLUDING DISCUSSIONS}

Increased environmental awareness of society and upcoming legislation are challenging the electrical and electronics industry to reduce the environmental impacts of WEEE and associated end-of-life costs. Despite the technological advances in electronics manufacturing, product recovery and recycling still remain cost/time bottlenecks in this sector and industry needs to come up with environmentally friendly and economically justifiable recycling plans for their products to remain competitive. The present paper has described a CARPP to improve the EOL recovery of EEE. It is argued that the adoption of such a systematical approach to the generation of bespoke recycling process plans for various products will significantly improve the environmental performance and will also maximize the 'value recovery' from recycling processes.

Currently, any used product that is received for the first time by a recovery facility is examined in an assessment workshop, before determining the recovery processes required to be used for the product. It is envisaged that the CARPP can be used within such assessment workshops to speed up, introduce consistency, and improve the development of bespoke recycling process plans that are based on the most up-to-date information and knowledge related to existing recycling processes. These recycling process plans can then be stored in an operational database and applied to similar product families in the future. A further use that is to be investigated for the CARPP is within the contemporary semi-automated recovery facilities. These facilities are being set up in various EU countries to process a large volume of a wide range of $\mathrm{E} \& \mathrm{E}$ products in response to the requirement for massive increase in recovery capacity to meet the target set by the WEEE directive. In such facilities, a product is pulled into a workstation from the conveyor belt feeding the line, is de-polluted, and selected disassembly is performed before the hulk is sent for shredding and separation processes further down the recovery line. In such applications, it is envisaged that the recycling process plans for various products generated and stored within CARPP can be fed directly to the recovery line via live computer platforms and used by the operators to identify the de-pollution and disassembly requirements to be undertaken on the product. Finally, the current authors argue that the information and knowledge contained in such CARPP will provide invaluable support for the design of future $\mathrm{E} \& \mathrm{E}$ products to improve their EOL recovery.

\section{REFERENCES}

1 European Commission. Proposal for a directive of the European Parliament and of the Council on Waste Electrical and Electronic Equipment and on the restriction of the use of certain hazardous substances in electrial and electronic equipment, COM (2000) 347 Final, Brussels.

2 Hesselbach, J., Herrmann, C., Ohlendorf, M., and Graf, R. Approach of substance flow oriented closed loop supply chain management in the electrical and electronic equipment industry. In Proceedings of the 2nd IEEE International Symposium on Environmentally conscious design and inverse manufacturing, Tokyo, Japan, 2001.

3 Marri, H. B., Gunasekaran, A., and Grieve, R. J. Computer-aided process planning: a state of art. Int. J. Advance Mfg Technol., 1998, 14(4), 261-268.

4 Reimer, B. M., Sodhi, S., and Knight, W. A. Optimizing electronics end-of-life disposal costs. In Proceedings of the IEEE International Symposium on Electronics and the environment, San Francisco, California, 2000.

5 Tsao, S. Recycling strategy for EOL cellular phone and cost-benefit analysis. Masters Thesis, Department of Resources Engineering, Cheng Kung University, Taiwan, 2001.

6 Stutz, M., Lichtenvort, K., and Pflieger, J. Green-cost management system for greening electrical and electronic equipment: methodology development and case studies. In Proceedings of the Fifth International Conference on Ecobalance, Tsukuba, Japan, 2002.

7 Tang, O., Grubbstrom, R. W., and Zanoni, S. Economic evaluation of disassembly processes in remanufacturing systems. Int. J. Prod. Res., 2004, 42(17), 3603-3617.

8 Gerner, S., Kobeissi, A., David, B., Binder, Z., and Descotes-Genon, B. Integrated approach for disassembly processes generation and recycling evaluation of an end-of-life product. Int. J. Prod. Res., 2005, 43(1), 195-222. 
9 Lee, S. G., Lye, S. W., and Khoo, M. K. A multi-objective methodology for evaluating product end-of-life options and disassembly. Int. J. Advance Mfg Technol., 2001, 18, $148-156$.

10 Zhang, H. C., Yu, Y., Jin, K., Ling, F. F., and Barnes, D. A decision-making model for materials management of end-of-life electronic products. J. Mfg Systems, 2000, 19(2), 94-107.

11 Huisman, J., Boks, C. B., and Stevels, A. L. N. Quotes for environmentally weighted recyclability (QWERTY): concept of describing product recyclability in terms of environmental value. Int. J. Prod. Res., 2003, 41(16), 3649-3665. 